\title{
Autism Spectrum Disorder and International Travel
}

\author{
Wee Xuan Neo ${ }^{1}$, Gerard Thomas Flaherty ${ }^{1,2^{*}}$ \\ ${ }^{1}$ School of Medicine, National University of Ireland Galway, Galway, Ireland \\ ${ }^{2}$ School of Medicine, International Medical University, Kuala Lumpur, Malaysia
}

Corresponding Author: Gerard Thomas Flaherty, MD, Professor, School of Medicine, National University of Ireland Galway, Galway, Ireland. Tel: +353-91495469, Fax: +353-91494540, Email: gerard.flaherty@nuigalway.ie

Received June 28, 2018; Accepted October 1, 2018; Online Published November 24, 2018

\begin{abstract}
The literature on international travellers with psychiatric disorders is limited. This perspective article highlights various travel-related aspects of autism spectrum disorder (ASD), including its aetiological association with maternal migration, the difficulties faced by longterm travelers with autistic children, and the facilitation of international travel for autistic individuals by the travel industry. Depending on the severity of their condition, autistic individuals may find specific aspects of the travel experience particularly distressing. Travel medicine practitioners should be aware of the unique needs of autistic travelers when providing pre-travel health counseling. There is also an onus on the travel industry to facilitate safe and enjoyable travel and remove barriers faced by autistic travellers.

Keywords: Migrants, Travel, Autistic Disorder, Mental Health
\end{abstract}

Citation: Neo WX, Flaherty GT. Autism spectrum disorder and international travel. Int J Travel Med Glob Health. 2019;7(1):1-3. doi:10.15171/ ijtmgh.2019.01.

\section{Introduction}

People living with mental illness are among the most vulnerable groups of international travellers., ${ }^{1,2}$ The literature on international travellers with psychiatric disorders is limited. ${ }^{3}$ Autism spectrum disorders (ASDs) comprise a group of neurodevelopmental disorders. Affected patients exhibit difficulties with communication and social interaction and demonstrate restricted, repetitive patterns of behavior, interest, and activities. ${ }^{4} \mathrm{~A}$ prevalence for ASD of $0.6 \%-1.13 \%$ has been reported, and there is a marked male predominance in this condition. ${ }^{5}$ Deka et al described the domestic travel patterns, needs, and barriers of adults with ASD in the United States and identified unique transportation challenges such as negotiating fixed-route transit and crossing roads safely. ${ }^{6}$ It can reasonably be assumed that overseas travel would pose even greater challenges for the autistic individual. This perspective article will reflect on various international travel-related aspects of ASD, including its putative link with maternal migration, the difficulties faced by long-term travelers with autistic children, and the facilitation of international travel for autistic individuals.

\section{Migration as a Risk Factor for Autism \\ Apart from the recognized underlying genetic causes such as fragile X syndrome, Rett syndrome and tuberous sclerosis, risk factors for ASD include advanced maternal age, ${ }^{7}$ preterm}

delivery, and intra-uterine growth restriction. Maternal migration has recently been postulated as an independent risk factor for the development of low-functioning ASD. A retrospective analysis of children presenting to the National Child Developmental Service in Ireland revealed an increased rate of low-cognitive functioning ASD in children born to mothers who migrated from sub-Saharan Africa. ${ }^{8}$ The authors hypothesize a role for maternal vitamin D deficiency as a basis for this phenomenon. The prevalence of ASD was three to four times higher in children born to Somali migrants than in a matched cohort. ${ }^{9}$ The majority of autistic children were male, and all affected children had evidence of intellectual disability. Most of the Somali mothers had resided in Sweden for the entire gestation period. A further Swedish study of almost 5000 children with ASD observed a lower risk of high-functioning autism and a higher risk of lowfunctioning autism in children of parents who had migrated from regions with a low human development index..$^{10} \mathrm{~A}$ case-control study of second-generation migrants in Finland found a positive association between ASD and the migration of both parents, immigrant mothers, but not immigrant fathers. ${ }^{11}$ Paradoxically, a lower prevalence of autism has been documented in the children of Hispanic migrants living in the United States, presumably owing to epigenetic changes resulting from larger social networks and improved obstetric outcomes. ${ }^{12}$

Copyright $(\odot 2019$ The Author(s). This is an open-access article distributed under the terms of the Creative Commons Attribution License (http:// creativecommons.org/licenses/by/4.0), which permits unrestricted use, distribution, and reproduction in any medium, provided the original work is properly cited. 


\section{Autism in Long-Term Travellers}

Modern approaches to the management of ASD in childhood emphasize theimportance of timely diagnosis and intervention, with access to multidisciplinary paediatric developmental services which can manage issues related to speech and language delay, motor problems, and behavioral challenges. Long-term travelers and expatriates whose children have been diagnosed with ASD may encounter difficulties in identifying and accessing reliable therapeutic services overseas. This may be compounded by discontinuities in care which may be detrimental to their special needs children. An example stems from the relocation abroad of families where one or more parents serve in the military. Frequent redeployment may hinder efforts to develop a therapeutic relationship with the autism care provider. Coupled with the lack of social support, this may lead to greater behavioral disturbances in affected children when parental redeployment compromises the continuity of family-centered care. ${ }^{13}$

\section{Challenges of Travel for Autistic Individuals}

Depending on the severity of their condition, autistic individuals may find specific aspects of the travel experience particularly distressing. The desire for predictability and maintenance of a fixed routine may be difficult to satisfy during international travel, especially where the travel itinerary itself is uncertain. ${ }^{14}$ Auditory overload may be prominent in airports and in crowded destinations with a high urban population density and traffic volume. Queuing in airports may be difficult for some travelers with ASD, and manual body searches at security stations may be poorly tolerated. A lack of familiarity with a foreign environment can provoke significant anxiety, depression, and social isolation in autistic travelers. A recent qualitative study of mothers of autistic children provided insight into the triggers of underlying emotional and behavioral disturbances, including the need to avoid spontaneous, unplanned, and highly stimulating activities during travel. ${ }^{15}$ The difficulties autistic children encounter during routine transportation were highlighted in a retrospective study of 82 children who had escaped from their child safety restraint during road travel. ${ }^{16}$ It is reasonable to suggest that these issues may be amplified during international travel, including on commercial airplanes and in taxis, with obvious safety implications for those involved.

\section{Role of the Travel Industry}

Travel medicine practitioners should be aware of the unique needs of autistic travelers when providing pre-travel health advice. There is also a responsibility on the travel industry to facilitate enjoyable travel and remove barriers faced by autistic travelers. A study from Northern Ireland evaluated a video modeling technique based on applied behavior analysis research to prepare autistic children for travel by airplane. ${ }^{17}$ Shannon Airport in the Republic of Ireland was the first airport in Europe to create a sensory room for autistic travelers which is located air-side, adjacent to the departure lounge. This quiet, dimly lit room is designed to provide relief from the hectic airport environment and includes features such as an undulating wavy wall, an aquatic bubble tube, color-changing, light-emitting diodes, and a wheel projector. There have been efforts to design tourism websites to make them more acceptable for travelers with ASD based on a greater use of icons, symbols, and simple text with less structural variation between webpages. ${ }^{18}$ Hamed underscored the need for quieter accommodations and a greater focus on nature tourism and exposure to cultural and historic sites of interest to the autistic traveler. ${ }^{19}$

\section{Conclusion}

Travel is a recognized risk factor for the development of autism in children whose mothers migrated during pregnancy. International travel poses significant challenges for autistic individuals, many of which can be addressed by promoting greater awareness throughout the travel industry about the special needs associated with this common psychiatric disorder. There is a need for greater qualitative research that would serve to illuminate aspects of the autistic travel experience which have not heretofore been discussed in the literature.

\section{Authors' Contributions}

Both authors contributed equally to the conception, planning, writing, and editing of the article. The final version was read and approved by both authors.

\section{Conflict of Interest Disclosures}

None declared.

\section{Ethical Approval}

Not applicable.

\section{Funding/Support}

None received.

\section{References}

1. Seeman MV. Travel risks for those with serious mental illness. Int J Travel Med Glob Health. 2016;4(3):76-81. doi:10.21859/ ijtmgh-040302.

2. Felkai P, Kurimay T. Patients with mental problems - the most defenseless travellers. J Travel Med. 2017;24(5). doi:10.1093/jtm/ tax005.

3. Flaherty GT, Lim Yap K. Bibliometric analysis and curriculum mapping of travel medicine research. J Travel Med. 2017;24(5). doi:10.1093/jtm/tax024.

4. American Psychiatric Association (APA). Diagnostic and Statistical Manual of Mental Disorders (DSM-V5). 5th ed. APA; 2013. doi:10.1176/appi.books.9780890425596.

5. Elsabbagh M, Divan G, Koh YJ, et al. Global prevalence of autism and other pervasive developmental disorders. Autism Res. 2012;5(3):160-179. doi:10.1002/aur.239.

6. Deka D, Feeley C, Lubin A. Travel patterns, needs, and barriers of adults with autism spectrum disorder: report from a survey. Transp Res Rec. 2016;2542:9-16. doi:10.3141/2542-02.

7. Sandin S, Hultman CM, Kolevzon A, Gross R, MacCabe JH, Reichenberg A. Advancing maternal age is associated with increasing risk for autism: a review and meta-analysis. J Am Acad Child Adolesc Psychiatry. 2012;51(5):477-486.e471. doi:10.1016/j.jaac.2012.02.018.

8. Bolton S, McDonald D, Curtis E, Kelly S, Gallagher L. Autism in a recently arrived immigrant population. Eur J Pediatr. 2014;173(3):337-343. doi:10.1007/s00431-013-2149-6. 
9. Barnevik-Olsson M, Gillberg C, Fernell E. Prevalence of autism in children born to Somali parents living in Sweden: a brief report. Dev Med Child Neurol. 2008;50(8):598-601. doi:10.1111/j.14698749.2008.03036.x.

10. Magnusson C, Rai D, Goodman A, et al. Migration and autism spectrum disorder: population-based study. $\mathrm{Br} J$ Psychiatry. 2012;201:109-115. doi:10.1192/bjp.bp.111.095125.

11. Lehti V, Hinkka-Yli-Salomaki S, Cheslack-Postava K, Gissler M, Brown AS, Sourander A. The risk of childhood autism among second-generation migrants in Finland: a case-control study. BMC Pediatr. 2013;13:171. doi:10.1186/1471-2431-13-171.

12. Palmer RF, Walker T, Mandell D, Bayles B, Miller CS. Explaining low rates of autism among Hispanic schoolchildren in Texas. Am J Public Health. 2010;100(2):270-272. doi:10.2105/ ajph.2008.150565.

13. Davis JM, Finke EH. The Experience of Military Families with Children with Autism Spectrum Disorders During Relocation and Separation. J Autism Dev Disord. 2015;45(7):2019-2034. doi:10.1007/s10803-015-2364-2.

14. Flaherty G, Md Nor MN. Travel itinerary uncertainty and the pre-travel consultation--a pilot study. J Travel Med. 2016;23(1). doi:10.1093/jtm/tav010.

15. Sedgley D, Pritchard A, Morgan N, Hanna P. Tourism and autism: Journeys of mixed emotions. Ann Tour Res. 2017;66:14-25. doi:10.1016/j.annals.2017.05.009.

16. Yonkman J, Lawler B, Talty J, O'Neil J, Bull M. Safely transporting children with autism spectrum disorder: evaluation and intervention. Am J Occup Ther. 2013;67(6):711-716. doi:10.5014/ ajot.2013.008250.

17. Ruddy L, Booth N, Gaw M, Liao Y, Dounavi K, Dillenburger K. Autism in the air: using point of view video priming and natural environment teaching to help children with autism travel by plane. Good Autism Practice. 2015;16(2):25-32.

18. Dattolo A, Luccio FL, Pirone E. Web accessibility recommendations for the design of tourism websites for people with autism spectrum disorders. Int J Adv Life Sci. 2016;8(3-4):297-308.

19. Hamed HM. Tourism and autism: An initiative study for how travel companies can plan tourism trips for autistic people. Am J Tour Manag. 2013;2(1):1-14. doi:10.5923/j.tourism.20130201.01. 